\title{
Effect of pre-operative neuromuscular training on functional outcome after total knee replacement: a randomized-controlled trial
}

\author{
Erika O Huber ${ }^{1,2^{*}}$, Rob A de Bie ${ }^{3}$, Ewa M Roos ${ }^{4}$ and Heike A Bischoff-Ferrari ${ }^{1}$
}

\begin{abstract}
Background: Total Knee Replacement (TKR) is the standard treatment for patients with severe knee osteoarthritis (OA). Significant improvement in pain and function are seen after TKR and approximately $80 \%$ of patients are very satisfied with the outcome. Functional status prior to TKR is a major predictor of outcome after the intervention. Thus, improving functional status prior to surgery through exercise may improve after surgery outcome. However, results from several previous trials testing the concept have been inconclusive after surgery.

Methods/design: In a randomized controlled trial (RCT) we will test the effect of a pre-operative neuromuscular trainingprogram versus an attention control program on lower extremity function - before and after surgery. We will enroll 80 participants, aged between 55-90 years, who are scheduled for TKR. In this single-blinded RCT, the intervention group will receive a minimum of 8 and a maximum of 24 training sessions plus 3 educational sessions of the knee school. The control group will receive the 3 educational sessions only. Assessments are performed immediately before and after the intervention (before surgery), at 6 weeks, 3 months and 12 months (after surgery). The primary outcome will include the Chair Stand Test as a measure of leg strength and reaction time. Secondary outcomes are knee function and pain assessed with the self-reported Knee Injury and Osteoarthritis Outcome Score (KOOS). All measurements will be carried out by a specially trained physical therapist, blinded to group allocation.

Discussion: To our knowledge this is the first single-blinded RCT to test the effect of pre-operative neuromuscular training plus knee school against knee school alone - on knee function and pain, assessed immediately after the interventions prior to surgery and repeatedly after surgery.
\end{abstract}

Trial registration: Clinical Trials NCT00913575

\section{Background}

Osteoarthritis (OA) is the most common joint disorder and a common cause of pain, loss of function and disability in older adults [1]. It is the second most common diagnosis made in older adults seeking medical care [2] and the leading cause of disability at older age [3]. When suffering from severe OA, Total Joint Replacement (TJR) is the preferred treatment option to significantly improve function and pain $[2,4]$. Given the demographic

\footnotetext{
* Correspondence: omega-e.huber@zhaw.ch

${ }^{1}$ Centre on Aging an Mobility, University Hospital Zurich and Waid City Hospital Zurich, University of Zurich, Gloriastrasse 25, Zurich 8091, Switzerland

${ }^{2}$ Institute of Physiotherapy, School of Health Professions, Zurich University of Applied Sciences, Technikumstrasse 71, Postfach, Winterthur 8401, Switzerland

Full list of author information is available at the end of the article
}

change with growing segment of the senior population in the Western World, the rate of these procedures will rise exponentially over the next decade. This will result in high health-care expenditures due to the absolute increase in TJR surgery (both direct hospital charges and indirect costs) [5].

The current EULAR (European League Against Rheumatism) recommendations include exercise as an effective treatment in the improvement of pain and function in patients with moderate to severe knee OA (effect size for validated outcome measures of pain and function versus placebo range from 0.57 to 1.0) [6]. Similarly, the OARSI (Osteoarthritis Research Society International) supports the benefits of exercise in patients with knee OA, both on pain and function [7].

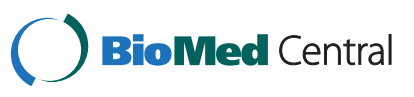


Notably, exercise alone may delay but not prevent TJR in severe OA [8]. Similarly, however, TJR does not fully restore function in many patients undergoing the procedure [9-11], which in part may be due to long-term mechanical impairments of the joint.

The most recent review published on pre-operative interventions for patients with hip or knee osteoarthritis awaiting joint replacement was published in 2011 and included 23 trials [12]. The authors concluded that there was low to moderate quality evidence for the benefit of pre-operative exercise for Total Knee Replacement (TKR). These data are consistent with three earlier systematic reviews [13-15].

Considering the evidence from the available formal reviews, two factors may have prevented a benefit from these programs: (A): Four trials had very small groups with a combined total of 137 subjects and were probably underpowered [16-19]. (B): The therapeutic validity as described by Hoogeboom et al. was not sufficient enough, making it unlikely, that interventions evaluated in these studies would have relevant effects [20].

In this study we aim to test a well-defined and feasible training program plus a knee school educational package against the educational package alone on lower extremity function and pain before and after TKR. The trial is powered based on pilot data and includes a detailed assessment of adherence to the program.

\section{Objective}

To study the effect of a pre-operative neuromuscular training plus knee school educational program compared to the educational program alone on lower extremity function and pain in individuals age 55-90 on a waiting list for TKR due to severe knee OA.

\section{Hypothesis}

Primary Endpoint: We hypothesize that patients undergoing a pre-operative neuromuscular training in addition to the educational program will be significantly quicker in performing the Chair Stand Test (test of lower extremity function) compared with those receiving the educational program alone immediately after the intervention and after TKR surgery.

Secondary Endpoints: We hypothesize that patients undergoing a pre-operative neuromuscular training in addition to the educational program will have a greater improvement in function and pain (KOOS subscales) compared with those receiving the educational program alone immediately after the intervention and after TKR surgery.

\section{Methods/design \\ Design}

The study design is a single-blinded randomized controlled trial (Figure 1).
Outcomes are measured at baseline (6-12 weeks preoperative: primary and secondary endpoints), 1 week pre-operative (after the intervention: primary and secondary endpoints), 6 weeks after surgery (secondary endpoints only), 3 months after surgery (primary and secondary endpoints) and 1 year after surgery (secondary endpoints only).

Prior to the baseline assessment eligible patients receive an information package on the study. The package includes detailed information, including their rights when participating in a research project and a written informed consent form. Ethic approval was granted by the Ethics Committee of the Cantons Aargau and Solothurn, Switzerland, approval number 2009/012.

Reporting of the RCT follows the recommendations of CONSORT guidelines for reporting of clinical trials and will be based on intent-to-treat [21]. In addition, a perprotocol analysis will be performed.

\section{Participants and recruitment}

We include individuals age 55-90 years on a waiting list for TKR due to severe primary or secondary OA. Individuals need to also be community dwelling and understand German as a written and spoken language. Exclusion criteria are cognitive impairment, revision surgery for TKR, plans to leave Switzerland before or after surgery, history of inflammatory arthritis and inability to walk at least 3 meters with or without walking aid.

The trial recruits at the Cantonal Hospital Olten and the Cantonal Hospital Aarau, which both perform about 200 TKRs per year. Recruitment and eligibility assessment are conducted by the orthopaedic surgeon at the time of consultation, when the patient has decided to undergo TKR surgery and is placed on the waiting list. Eligible patients are referred to the study centre (Centre on Aging and Mobility, University of Zurich) by fax. The referring surgeon gives eligible patients a onepage summary of the study. After confirming their interest, eligible individuals receive a detailed participant information about the study procedure and 4-7 days later, they are contacted by phone $(\mathrm{EOH})$ to answer additional questions. Eligible and willing individuals then provide their written informed consent. Two experienced physical therapists (assessors), not working at the recruitment sites and not being involved in the neuromuscular training and the knee school, have been specifically trained for the assessments of this study and are blinded to the randomization.

Neuromuscular training and knee school take place at the recruitment sites. Several experienced physical therapists working at the recruitment sites, have been specially trained either for the neuromuscular training or the knee school. Individuals of the intervention group 


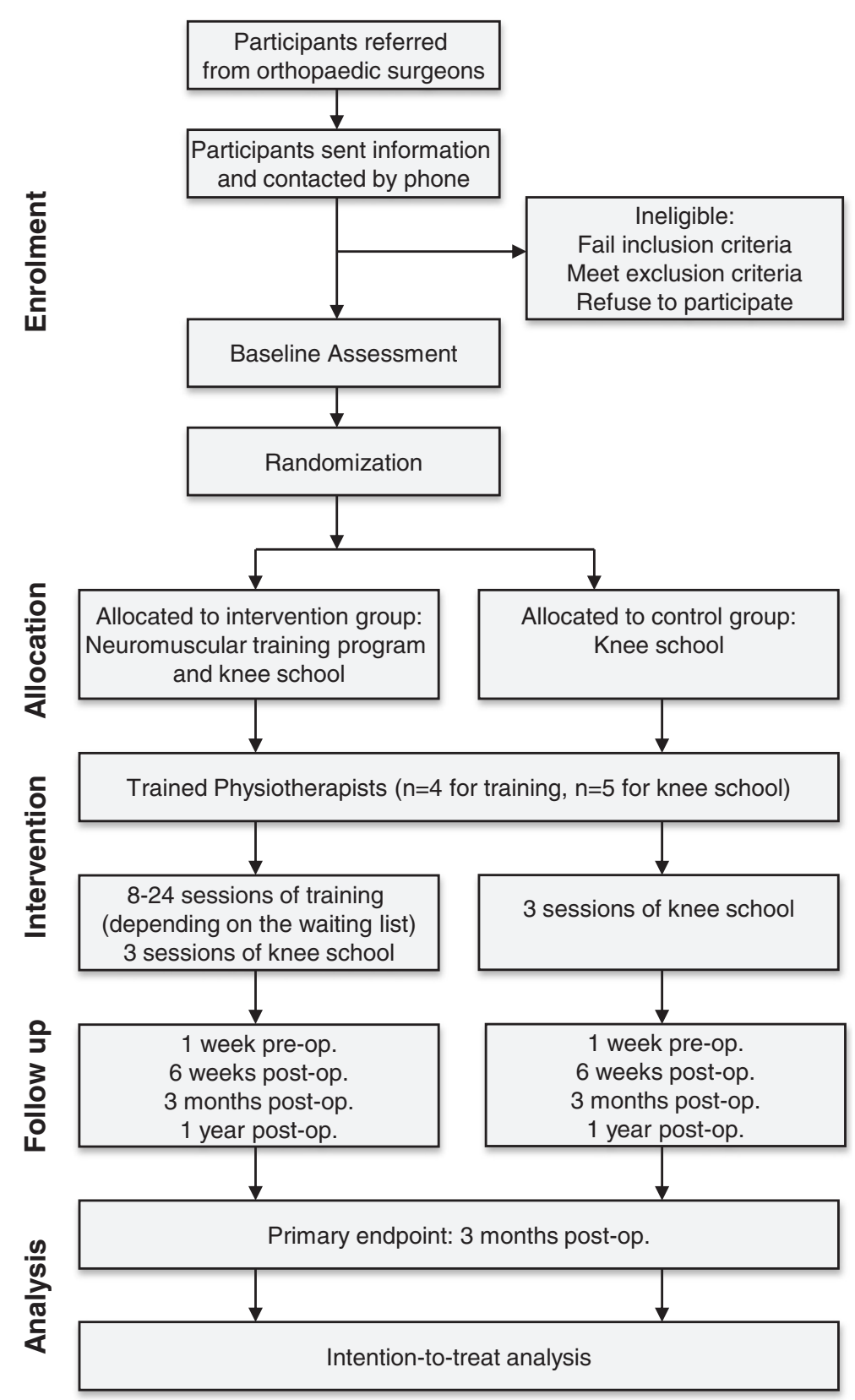

Figure 1 Flow chart of research design.

and individuals of the control group were not together in the knee school.

\section{Baseline assessment and randomization}

After informed consent, the assessor performs the baseline assessment at the recruitment site. Additionally, demographics and covariates that affect outcomes are documented: age, gender, height, weight, cognitive impairment (assessed with the Folstein Mini Mental score) [22] and risk of extended inpatient rehabilitation (measured with the Risk Assessment and Predictor Tool (RAPT) [23].

Participants will be randomized using block allocation with a block size of four. The list is computer generated by the independent randomization centre.

The coordinating investigator (EOH) informs the participant about the group allocation and schedules the treatment sessions as allocated by the independent randomization centre. 


\section{Interventions}

\section{Neuromuscular training program (NEMEX-TJR training program)}

The neuromuscular training follows the principles of neuromuscular and biomechanical training as described in the neuromuscular training method NEuroMuscular EXercise (NEMEX) [24], and aims to improve neuromuscular control (also called sensorimotor control) and to achieve compensatory functional stability. Neuromuscular control is defined as the ability to produce controlled movement through coordinated muscle activity. Movement starts with the non-affected leg to facilitate the bilateral transfer effect of motor learning. Exercises are mainly performed in closed kinetic chains in the lying, sitting or standing position to achieve muscular co-activation in an appropriate position of the joints with hip, knee and foot well aligned. These activities emphasize the improvement of the stabilizing functions of the weight-bearing muscles for better postural control in static and dynamic situations. Open kinetic chains are only performed to improve muscle strength of the knee and hip muscles.

The training takes place in groups under the supervision of an experienced and especially trained physical therapist and consists of three parts:

- Part 1 Warming up: The warm-up period consists of ergometer cycling for 10 minutes. The workload is set individually and can be increased during the 10 minutes.

- Part 2 Circuit program: The circuit program comprises four exercise circles, with the key elements: core stability/postural function, functional alignment, lower-extremity muscle strength and functional exercises. Usually two exercises, sometimes one, are performed in each circle. Each exercise is performed $2-3$ sets $* 10-15$ repetitions, with rest between each exercise and circle. To allow progression three levels of difficulty are defined. Progression is provided by varying in number, direction and velocity of the movements, by increasing the load and/or by changing the support surface. Progression is made when an exercise is performed of 3 sets * 15 repetitions with good neuromuscular control and good quality of performance (based on visual inspection by the physical therapist) and with minimal exertion and control of the movement (perceived by the patient).

- Part 3: Cooling down: The cooling down period of about 10 minutes consists of forward and backward walking exercises, about 10 meters in each direction, mobility exercises for the lower extremities and stretching exercises for the lower-extremity muscles.
The exercises included in the training program are described in detail in the Additional file 1 [24].

Documentation of the training program includes the number of training sessions, level of difficulty per session, pain on a 0 to 10 scale before and after each session and 24 hours after each session.

Patients also document how physically active they were per training week (activity levels A-C), notified in minutes per activity level. Level A consists of competitive sports activities, intensive enough to cause heavy sweating. Level B consists of endurance or muscle strengthening activities, intense enough to cause light sweating and faster breathing while still allowing one to talk, i.e. increased walking, running, cycling, swimming, cross-country skiing or muscle strength training. Level $\mathrm{C}$ consists of activities of daily living, i.e. walking, climbing stairs, housekeeping or garden work [25].

\section{Knee school}

The knee school was designed to educate participants about knee OA, the preparation phase before undergoing TKR and the acute rehabilitation phase afterwards. The concept of the knee school is adapted from the hip school, described by Klassbo [26]. The knee school is taught by an experienced and especially trained physical therapist over 3 individual or group sessions, one session per week, starting about 4 weeks before the operation. Knee school sessions are separately organised for participants of the intervention group and those of the control group to avoid contamination.

The content of the school includes information about anatomy of the knee joint and adjacent functional structures, recommended activities with prosthesis and postoperative pain management, and details on the postoperative rehabilitation phase. Didactical elements include models of the knee joint and the lower extremity, working sheets, photos and videos, hand outs, PowerPoint presentations and peer discussions.

\section{Intervention group}

Participants of the intervention group receive 8-24 sessions of the neuromuscular training program prior to TKR surgery depending on location of the waiting list for surgery. Participants also receive 3 sessions of the knee school starting about 4 weeks before surgery.

\section{Control group}

Participants of the control group receive 3 sessions of the knee school, starting about 4 weeks before surgery.

\section{Outcome measures}

We include one objective (Chair Stand Test) and two patient-reported outcome measures (pain and function subscale of the KOOS questionnaire) in this trial to test 
the effect of the intervention on lower extremity function (see Table 1).

\section{Primary outcome measure}

The primary outcome is the Chair Stand Test, also known as the repeated sit-to-stand test. It is commonly used as a measure of lower extremity strength, balance and reaction time [27-29]. The subject is asked, to stand up from a chair without armrests to a fully erect standing position five times as quickly as possible without pushing off [30]. The time needed is measured by a stop watch in seconds. The Chair Stand Test is easy to perform in clinical practice and has shown excellent intraand inter-rater reliability (Inter Class Correlation, 0.89 [31]. The Chair Stand Test was also found to predict disability across populations accurately [32].

\section{Secondary outcome measure}

Secondary outcomes are knee pain and function assessed by the KOOS questionnaire. The KOOS is a commonly used patient-reported outcome with overall acceptable psychometric properties to evaluate patients with knee injury and knee OA [33], including those having TKR [34]. KOOS holds 5 subscales with a total of 42 items: 1) pain, 2) other symptoms, 3) function in daily living (ADL), 4) function in sport and recreation and 5) kneerelated quality of life. Since exercise training is aiming to improve function we are particularly interested in the KOOS ADL subscale for the functional outcome measure.

The German version of the KOOS is used in this trial [35]. Its user's guide including scoring instructions, are available from http://www.koos.nu.

\section{Additional outcome measures}

Lower limb function Isometric muscle strength of knee flexors and extensors, hip flexors, hip extensors, hip adductors and hip abductors are measured with a handheld pull gauge [36,37]. The ability to alternate rapidly between concentric and eccentric work of the extensor muscles of the hip and knee is impaired in many patients with knee OA [38]. The ability of rapid alternation between concentric and eccentric function is measured using maximal number of knee-bending in 30 seconds, which is a valid and reliable test (ICC, 0.80) [24,39]. Range of motion is measured with a long-arm goniometer [40]. Walking speed is assessed with the $20 \mathrm{~m}$ walk test (ICC, 0.93) [24], a reliable modification of the short walk test used in many epidemiological and clinical studies. The test measures the time it takes to walk 20 meters at the participant's usual walking pace, along with the number of steps that they take to walk 20 meters [41]. Lower extremity mobility is further assessed with the Timed Up and Go test, which requires a person to rise from a stair, walk 4 meters, turn $180^{\circ}$, return to the chair and sit down [42].

Table 1 Summary of measures to be collected

\begin{tabular}{|c|c|c|c|c|c|c|}
\hline Primary outcome measure & $\begin{array}{l}\text { 6-12 weeks } \\
\text { pre-op. }\end{array}$ & $\begin{array}{l}1 \text { week } \\
\text { pre-op. }\end{array}$ & at discharge & $\begin{array}{l}6 \text { weeks } \\
\text { post-op. }\end{array}$ & $\begin{array}{l}3 \text { months } \\
\text { post-op. }\end{array}$ & $\begin{array}{l}1 \text { year } \\
\text { post-op. }\end{array}$ \\
\hline Chair Stand Test & $x$ & $x$ & & & $x$ & \\
\hline \multicolumn{7}{|l|}{ Secondary outcome measure } \\
\hline Subscales pain and function of the KOOS & $x$ & $x$ & & $x$ & $x$ & $x$ \\
\hline \multicolumn{7}{|l|}{ Additional outcome measures } \\
\hline Muscle strength & $x$ & $x$ & & & $X$ & \\
\hline Knee-bending/30s & $x$ & $x$ & & & $x$ & \\
\hline Range of motion of the knee & $x$ & $x$ & & & $x$ & \\
\hline $20 \mathrm{~m}$ walk test & $x$ & $x$ & & & $x$ & \\
\hline Timed up and go & $x$ & $x$ & & & $x$ & \\
\hline Physical activity level & $x$ & $x$ & & $x$ & $x$ & $x$ \\
\hline Adapted NHANES III & $x$ & $x$ & & $x$ & $x$ & $x$ \\
\hline SF 36 & $x$ & $x$ & & $X$ & $x$ & $x$ \\
\hline EQ-5D & $x$ & $x$ & & $x$ & $x$ & $x$ \\
\hline RAPT & $x$ & & & & & \\
\hline LOS & & & $x$ & & & \\
\hline Minutes of nursing care & & & $x$ & & & \\
\hline $\begin{array}{l}\text { KOOS Knee injury and Osteoarthritis Outcome } \\
\text { NHANES National Health And Nutrition Exami } \\
\text { SF } 36 \text { Short Form- } 36 \text { health survey. } \\
\text { EQ-5D EuroQol - } 5 \text { dimensions. } \\
\text { RAPT Risk Assessment and Predictor Tool. } \\
\text { LOS Length of stay. }\end{array}$ & Survey. & & & & & \\
\hline
\end{tabular}


Physical activity and health-related quality of life Physical activity is measured by the SenseWear armband, a device for quantifying physical activity in daily life $[43,44]$. It collects the following data: energy expenditure, average MET's, physical activity duration, steps per day and the physical activity distribution (sedentary, moderate, vigorous and very vigorous). In addition, physical activity is measured by 10 activity questions assessed and validated in NHANES III $[45,46]$. Health-related quality of life is measured by the generic questionnaire SF-36 [47,48]. General health status is measured by the EuroQoL (EQ-5D). The EQ-5D is used to complement the SF-36, allowing health economic evaluation and comparison to other knee OA populations [49].

Health service utilization Discharge potential is measured by the Risk Assessment and Predictor Tool (RAPT), a 6 question tool which scores patients into low, middle or high risk for extended inpatient rehabilitation [23].

Length of Stay (LOS) and minutes of care by the nursing staff (including all activities delivered to the patients, e.g. mobilisation, washing, medication) are measured by LEP $^{\circledR}$, which is a tool used for workload management in nursing [50]. Both measurements are taken at discharge in the acute care hospital.

\section{Sample size calculation}

The sample size calculation is based on the primary endpoint - the Chair Stand Test. We assume that the mean difference in change over time between groups is $7.3 \mathrm{sec}-$ onds (corresponding to means of 8.3 and 1.0, respectively) and the common within-group standard deviation is 7.3. This effect was selected based on pilot data of an uncontrolled trial in knee OA patients [24], assuming that our control group (without exercise training) would not improve over time while awaiting TKR. It is also assumed that the effect size is reasonable, in the sense that an effect of this magnitude could be anticipated in this field of research. Alpha has been set at 0.05 and the power has been set at 0.9 . In each group 25 patients are needed.

Assuming a drop-out rate of $12 \%$, we will include 40 patients per group.

\section{Analysis plan}

All analyses are based on intent-to-treat, including all randomized individuals who had at least 1 intervention session. We will use linear regression to evaluate the effect of our training program plus knee school against knee school alone for both the primary and secondary endpoints - after the training and at 3 months after surgery. The multivariate analyses for the primary endpoint
(Chair Stand Test) and secondary endpoints (pain and function subscales of the KOOS) will control for baseline function of the respective endpoint, age in years, gender, and baseline body mass index. To account for the reduced exposure time to the training intervention for participants who were on a short waiting list or were less adherent we will perform subgroup analyses by training exposure groups (we will use the median as a cut-off for lower and higher intensity of the training program based on number of training sessions attended).

To evaluate a benefit of the training program on patient-reported pain and function across all time points, we will use repeated measures linear regression analyses controlling for baseline strength/function, time, age, gender, and body mass index.

Analyses will be conducted with $\mathrm{R}$ version 2.14 .1 software. All P values are two-sided.

\section{Discussion}

This randomized controlled trial will compare the effect of pre-operative neuromuscular training plus knee school with knee school alone on lower extremity function. The feasible training program aims to improve the activity-oriented outcome measures. The knee school serves both as an addition to the training as well as an attention control strategy in the control group. As an integral part of this trial, we assess adherence to the training intervention, which will allow per protocol analyses in addition to the primary intent-to-treat analyses.

$\mathrm{OA}$ is a key driver of disability at older age and is the fourth most common condition in older women and the eight most common in older men [6,51]. Given the demographic development with a rising segment of the senior population, and therefore improving functionality in individuals with $\mathrm{OA}$ is a public health target. Our trial aims to contribute important knowledge on whether to what extend a pre-operative training among patients on a waiting list for TKR will improve their functionality before and after surgery. The interest in the effect of pre-operative interventions has increased in the last decade, which is seen by the increasing number of publications. The evidence is up to now for different reasons moderate and a conclusive answer is not yet possible [12,52].

Our trial will also contribute to evidence-based guidelines to help physicians and patients make informed decisions [53]. With respect to patient functional status, the major predictor of patient functional status postoperatively is pre-operative status [54]. It is therefore important to test the benefit of pre-operative training in patients undergoing TKR and our trial could contribute to a definition of pre-operative treatment recommendations or guidelines. 


\section{Additional file}

\section{Additional file 1: NEMEX-TJR training program. Detailed description} of the exercises.

\section{Abbreviations}

TKR: Total Knee Replacement; OA: Osteoarthritis; RCT: Randomized Controlled Trial; KOOS: Knee Injury and Osteoarthritis Outcome Score; TJR: Total Joint Replacement; EULAR: European League Against Rheumatism;

OARSI: Osteoarthritis Research Society International; RAPT: Risk Assessment and Predictor Tool; NEMEX: NEuroMuscular Exercise; ADL: Activities of daily living; MET: Metabolic Equivalent of Task; NHANES: National Health And Nutrition Examination Survey; SF-36: Short Form-36 health survey; EQ-

5D: EuroQol - 5 dimensions; QoL: Quality of Life; LOS: Length of Stay.

\section{Competing interests}

The authors declare that they have no competing interests.

\section{Authors' contributions}

$\mathrm{EOH}$ originated the idea of the study. $\mathrm{EOH}$ and $\mathrm{HBF}$ designed the trial protocol with assistance from EMR and RAB. EOH drafted the manuscript and the other authors revised it critically and corrected draft versions. All authors read and approved the final manuscript

\section{Acknowledgements}

The authors would like to acknowledge Eva Lundberg and Anne Link, Department of Health Sciences Lund University, Lund, Sweden for their support by the instruction of the physical therapists, who treat the participants in the intervention group.

The project is supported by the Albert Böni Stiftung, Zurich, Switzerland, a foundation for research in Rheumatology and Physical Medicine.

\section{Author details}

${ }^{1}$ Centre on Aging an Mobility, University Hospital Zurich and Waid City Hospital Zurich, University of Zurich, Gloriastrasse 25, Zurich 8091, Switzerland. ${ }^{2}$ Institute of Physiotherapy, School of Health Professions, Zurich University of Applied Sciences, Technikumstrasse 71, Postfach, Winterthur 8401, Switzerland. ${ }^{3}$ Department of Epidemiology, CAPHRI School of Public Health and Primary Care, Maastricht University, Maastricht, The Netherlands. ${ }^{4}$ Institute of Sports Science and Clinical Biomechanics, University of Southern Denmark, Campusvey 55, Odense M 5230, Denmark.

Received: 21 March 2013 Accepted: 25 April 2013

Published: 3 May 2013

\section{References}

1. Arden N, Nevitt MC: Osteoarthritis: epidemiology. Best Pract Res Clin Rheumatol 2006, 20(1):3-25

2. Harris $W H$, Sledge CB: Total hip and total knee replacement (2). N Engl J Med 1990, 323(12):801-807.

3. Guccione AA, Felson DT, Anderson JJ, Anthony JM, Zhang Y, Wilson PW Kelly-Hayes M, Wolf PA, Kreger BE, Kannel WB: The effects of specific medical conditions on the functional limitations of elders in the Framingham Study. Am J Public Health 1994, 84(3):351-358.

4. Harris WH, Sledge CB: Total hip and total knee replacement (1). N Engl J Med 1990, 323(11):725-731.

5. Schweizerisches Gesundheitsobservatorium: Gesundheit in der Schweiz. Nationaler Gesundheitsbericht. 2008. http://www.obsan.admin.ch.

6. Jordan KM, Arden NK, Doherty M, Bannwarth B, Bijlsma JW, Dieppe P, Gunther K, Hauselmann H, Herrero-Beaumont G, Kaklamanis P, et al: EULAR Recommendations 2003: an evidence based approach to the management of knee osteoarthritis: Report of a Task Force of the Standing Committee for International Clinical Studies Including Therapeutic Trials (ESCISIT). Ann Rheum Dis 2003, 62(12):1145-1155.

7. Zhang W, Nuki G, Moskowitz RW, Abramson S, Altman RD, Arden NK, Bierma-Zeinstra S, Brandt KD, Croft P, Doherty M, et al: OARSI recommendations for the management of hip and knee osteoarthritis: part III: Changes in evidence following systematic cumulative update of research published through January 2009. Osteoarthr Cartil 2010, 18(4):476-499.
8. Ethgen O, Bruyere O, Richy F, Dardennes C, Reginster JY: Health-related quality of life in total hip and total knee arthroplasty. A qualitative and systematic review of the literature. J Bone Joint Surg Am 2004, 86-A(5):963-974.

9. Bischoff-Ferrari HA, Lingard EA, Losina E, Baron JA, Roos EM, Phillips CB, Mahomed NN, Barrett J, Katz JN: Psychosocial and geriatric correlates of functional status after total hip replacement. Arthritis Rheum 2004, 51(5):829-835.

10. Nilsdotter AK, Petersson IF, Roos EM, Lohmander LS: Predictors of patient relevant outcome after total hip replacement for osteoarthritis: a prospective study. Ann Rheum Dis 2003, 62(10):923-930.

11. Karlson EW, Mandl LA, Aweh GN, Sangha O, Liang MH, Grodstein F: Total hip replacement due to osteoarthritis: the importance of age, obesity, and other modifiable risk factors. Am J Med 2003, 114(2):93-98.

12. Wallis JA, Taylor NF: Pre-operative interventions (non-surgical and non-pharmacological) for patients with hip or knee osteoarthritis awaiting joint replacement surgery-a systematic review and metaanalysis. Osteoarthr Cartil 2011, 19(12):1381-1395

13. Coudeyre E, Jardin C, Givron P, Ribinik P, Revel M, Rannou F: Could preoperative rehabilitation modify postoperative outcomes after total hip and knee arthroplasty? Elaboration of French clinical practice guidelines. Ann Readapt Med Phys 2007, 50(3):189-197.

14. Ackerman IN, Bennell KL: Does pre-operative physiotherapy improve outcomes from lower limb joint replacement surgery? A systematic review. Aust J Physiother 2004, 50(1):25-30.

15. Dauty $M$, Genty $M$, Ribinik P: Physical training in rehabilitation programs before and after total hip and knee arthroplasty. Ann Readapt Med Phys 2007, 50(6):462-468. 455-461.

16. Weidenhielm L, Mattsson E, Brostrom LA, Wersall-Robertsson E: Effect of preoperative physiotherapy in unicompartmental prosthetic knee replacement. Scand J Rehabil Med 1993, 25(1):33-39.

17. D'Lima DD, Colwell CW Jr, Morris BA, Hardwick ME, Kozin F: The effect of preoperative exercise on total knee replacement outcomes. Clin Orthop Relat Res 1996, 326:174-182.

18. Rodgers JA, Garvin KL, Walker CW, Morford D, Urban J, Bedard J: Preoperative physical therapy in primary total knee arthroplasty. J Arthroplasty 1998, 13(4):414-421.

19. Rooks DS, Huang J, Bierbaum BE, Bolus SA, Rubano J, Connolly CE, Alpert S, Iversen MD, Katz JN: Effect of preoperative exercise on measures of functional status in men and women undergoing total hip and knee arthroplasty. Arthritis Rheum 2006, 55(5):700-708.

20. Hoogeboom TJ, Oosting E, Vriezekolk JE, Veenhof C, Siemonsma PC, de Bie $\mathrm{RA}$, van den Ende $\mathrm{CH}$, van Meeteren $\mathrm{NL}$ : Therapeutic validity and effectiveness of preoperative exercise on functional recovery after joint replacement: a systematic review and meta-analysis. PLoS One 2012 7(5):e38031

21. Boutron I, Moher D, Altman DG, Schulz KF, Ravaud P: Extending the CONSORT statement to randomized trials of nonpharmacologic treatment: explanation and elaboration. Ann Intern Med 2008, 148(4):295-309.

22. Folstein MF, Folstein SE, MCHugh PR: Mini-mental state A practical method for grading the cognitive state of patients for the clinician. J Psychiatr Res 1975, 12(3):189-198.

23. Oldmeadow LB, McBurney H, Robertson VJ: Predicting risk of extended inpatient rehabilitation after hip or knee arthroplasty. J Arthroplasty 2003, 18(6):775-779

24. Ageberg E, Link A, Roos EM: Feasibility of neuromuscular training in patients with severe hip or knee OA: the individualized goal-based NEMEX-TJR training program. BMC Musculoskelet Disord 2010, 11:126

25. Swiss Federal Office of Sports SFOoPH, Health Promotion Switzerland Network HEPA Switzerland: Health Enhancing Physical Activity. A Base Document. http://www.hepa.ch.

26. Klassbo M, Larsson G, Harms-Ringdahl K: Promising outcome of a hip school for patients with hip dysfunction. Arthritis Rheum 2003 49(3):321-327

27. Bohannon RW: Alternatives for measuring knee extension strength of the elderly at home. Clin Rehabil 1998, 12(5):434-440.

28. Bohannon RW: Sit-to-stand test for measuring performance of lower extremity muscles. Percept Mot Skills 1995, 80(1):163-166.

29. Lord SR, Murray SM, Chapman K, Munro B, Tiedemann A: Sit-to-stand performance depends on sensation, speed, balance, and psychological 
status in addition to strength in older people. J Gerontol A Biol Sci Med Sci 2002, 57(8):M539-M543.

30. Whitney SL, Wrisley DM, Marchetti GF, Gee MA, Redfern MS, Furman JM: Clinical measurement of sit-to-stand performance in people with balance disorders: validity of data for the Five-Times-Sit-to-Stand Test. Phys Ther 2005, 85(10):1034-1045.

31. Villadsen A, Roos EM, Overgaard S, Holsgaard-Larsen A: Agreement and reliability of functional performance and muscle power in patients with advanced osteoarthritis of the hip or knee. Am J Phys Med Rehabil / Assoc Acad Physiatrists 2012, 91(5):401-410.

32. Guralnik JM, Ferrucci L, Simonsick EM, Salive ME, Wallace RB: Lowerextremity function in persons over the age of 70 years as a predictor of subsequent disability. N Engl J Med 1995, 332(9):556-561.

33. Collins NJ, Misra D, Felson DT, Crossley KM, Roos EM: Measures of knee function: International Knee Documentation Committee (IKDC) Subjective Knee Evaluation Form, Knee Injury and Osteoarthritis Outcome Score (KOOS), Knee Injury and Osteoarthritis Outcome Score Physical Function Short Form (KOOS-PS), Knee Outcome Survey Activities of Daily Living Scale (KOS-ADL), Lysholm Knee Scoring Scale, Oxford Knee Score (OKS), Western Ontario and McMaster Universities Osteoarthritis Index (WOMAC), Activity Rating Scale (ARS), and Tegner Activity Score (TAS). Arthritis Care Res (Hoboken) 2011, 63(Suppl 11):S208-S228.

34. Roos EM: Effectiveness and practice variation of rehabilitation after joint replacement. Curr Opin Rheumatol 2003, 15(2):160-162.

35. Kessler S, Lang S, Puhl W: Stove J: [The Knee Injury and Osteoarthritis Outcome Score-a multifunctional questionnaire to measure outcome in knee arthroplasty]. Z Orthop Ihre Grenzgeb 2003, 141(3):277-282.

36. Stoll T, Huber E, Seifert B, Michel BA, Stucki G: Maximal isometric muscle strength: normative values and gender-specific relation to age. Clin Rheumatol 2000, 19(2):105-113.

37. Huber E, Stoll T, Ehrat B, Hofer HO, Seifert B, Stucki G: Zuverlässigkeit und Normperzentilen einer neuen isometrischen Muskelkraftmessmethode. Physiotherapie SPV 1997, 33(9):29-39.

38. Hortobagyi T, Garry J, Holbert D, Devita P: Aberrations in the control of quadriceps muscle force in patients with knee osteoarthritis. Arthritis Rheum 2004, 51(4):562-569.

39. Roos EM, Bremander AB, Englund M, Lohmander LS: Change in selfreported outcomes and objective physical function over 7 years in middle-aged subjects with or at high risk of knee osteoarthritis. Ann Rheum Dis 2008, 67(4):505-510.

40. Lenssen AF, van Dam EM, Crijns YH, Verhey M, Geesink RJ, van den Brandt PA, de Bie RA: Reproducibility of goniometric measurement of the knee in the in-hospital phase following total knee arthroplasty. BMC Musculoskelet Disord 2007, 8:83

41. Faulkner KA, Redfern MS, Rosano C, Landsittel DP, Studenski SA, Cauley JA, Zmuda JM, Simonsick EM, Kritchevsky SB, Newman AB: Reciprocal influence of concurrent walking and cognitive testing on performance in older adults. Gait Posture 2006, 24(2):182-189.

42. Podsiadlo D, Richardson S: The timed "Up \& Go": a test of basic functional mobility for frail elderly persons. J Am Geriatr Soc 1991, 39(2):142-148.

43. Pitta F, Troosters T, Probst VS, Spruit MA, Decramer M, Gosselink R: Quantifying physical activity in daily life with questionnaires and motion sensors in COPD. Eur Respir J 2006, 27(5):1040-1055.

44. Holsgaard-Larsen A, Roos EM: Objectively measured physical activity in patients with end stage knee or hip osteoarthritis. Eur J Phys Rehabil Med 2012, 48(4):577-585

45. Bischoff-Ferrari HA, Dietrich T, Orav EJ, Hu FB, Zhang Y, Karlson EW, Dawson-Hughes B: Higher 25-hydroxyvitamin D concentrations are associated with better lower-extremity function in both active and inactive persons aged $>$ or $=60$ y. Am J Clin Nutr 2004, 80(3):752-758.

46. Nelson KM, Reiber G, Boyko EJ: Diet and exercise among adults with type 2 diabetes: findings from the third national health and nutrition examination survey (NHANES III). Diabetes Care 2002, 25(10):1722-1728.

47. Ware JE: Measuring patients' views: the optimum outcome measure. BMJ 1993, 306(6890):1429-1430.

48. Ware JE Jr, Sherbourne CD: The MOS 36-item short-form health survey (SF-36). I. Conceptual framework and item selection. Med Care 1992, 30(6):473-483

49. Rabin R, de Charro F: EQ-5D: a measure of health status from the EuroQol Group. Ann Med 2001, 33(5):337-343.

50. LEP - Leistungen sichtbar machen. [http://www.lep.ch]
51. Zhang W, Doherty M, Peat G, Bierma-Zeinstra MA, Arden NK, Bresnihan B Herrero-Beaumont G, Kirschner S, Leeb BF, Lohmander LS, et al: EULAR evidence-based recommendations for the diagnosis of knee osteoarthritis. Ann Rheum Dis 2010, 69(3):483-489.

52. Gill SD, McBurney $\mathrm{H}$ : Does exercise reduce pain and improve physical function before hip or knee replacement surgery? A systematic review and meta-analysis of randomized controlled trials. Arch Phys Med Rehabil 2013, 94(1):164-176.

53. Westby MD: Exercise can improve the outcomes in hip and knee replacement surgery. Rheumatologist 2008, 2(9):16-18.

54. Katz JN: Total joint replacement in osteoarthritis. Best Pract Res Clin Rheumatol 2006, 20(1):145-153.

doi:10.1186/1471-2474-14-157

Cite this article as: Huber et al:: Effect of pre-operative neuromuscular training on functional outcome after total knee replacement: a randomized-controlled trial. BMC Musculoskeletal Disorders 2013 14:157.

\section{Submit your next manuscript to BioMed Central and take full advantage of:}

- Convenient online submission

- Thorough peer review

- No space constraints or color figure charges

- Immediate publication on acceptance

- Inclusion in PubMed, CAS, Scopus and Google Scholar

- Research which is freely available for redistribution 